\title{
Identifikasi Inovasi dan Kinerja Bisnis dalam Meningkatkan Daya Saing
}

\section{Identification of Innovation and Business Performance in Enhance Competitiveness}

\author{
Maraya Azizah Rashin \& Astri Ghina \\ Universitas Telkom, Bandung, Jawa Barat, Indonesia \\ marayazhr@gmail.com,astrighina@telkomuniversity.ac.id \\ Naskah diterima tanggal 9/6/2018, Direvisi akhir tanggal 15/7/2018, disetujui tanggal 15/8/2018
}

\begin{abstract}
Abstrak
Dengan meningkatnya jumlah Usaha Mikro, Kecil, dan Menengah (UMKM) di Indonesia dan industri fashion di Kota Bandung, para pelaku usaha dituntut melakukan inovasi agar menjadi yang terbaik diantara pesaing lainnya sehingga dapat meningkatkan daya saing dan kinerja bisnis perusahaan. PT. Dharma Adi Mandiri, merupakan sebuah perusahaan yang bergerak di dalam industri fashion di Indonesia yang mempunyai brand bernama Applecoast dan telah meluncurkan brand terbarunya yaitu Noore Hijab Sport. Penelitian ini dilakukan untuk mengidentifikasi inovasi pada inovasi produk, inovasi proses dan inovasi pemasaran yang telah dilakukan oleh PT. Dharma Adi Mandiri. Selain itu, peneliti juga mengidentifikasi kinerja bisnis yang dilihat dari aspek profitability, sales volume dan market share. Penelitian ini merupakan penelitian kualitatif dengan penyajian secara deskriptif. Data diperoleh dengan wawancara, observasi dan dokumentasi. Sumber data dalam penelitian ini adalah pemilik dari PT. Dharma Adi Mandiri, Purchasing and GA di Noore, dan Area Manajer di Applecoast. Teknik keabsahan data dalam penelitian ini menggunakan triangulasi sumber. Berdasarkan hasil penelitian ini, maka dapat disimpulkan bahwa PT. Dharma Adi Mandiri telah melakukan beberapa inovasi pada aspek inovasi produk, inovasi proses dan inovasi pemasaran. Kemudian kinerja bisnis pada PT. Dharma Adi Mandiri telah menghasilkan kinerja bisnis yang lebih baik dilihat dari aspek profitability, sales volume dan market share yang mengalami pertumbuhan. Hambatan dalam merealisasikan produk terdapat di supply chain, maka disarankan agar PT. Dharma Adi Mandiri diharapkan mampu menyempurnakan supply chain agar menjadi efisien.
\end{abstract}

Kata kunci: inovasi, kinerja bisnis, dan UMKM.

\begin{abstract}
With the increasing number ofMicro, Small and Medium Enterprises (MSMEs) in Indonesia and the fashion industry in Bandung, business actors are required to innovate to be the best among other competitors so as to improve the competitiveness and business performance of the company. PT. Dharma Adi Mandiri, is a company engaged in the fashion industry in Indonesia which has a brand called Applecoast and has launched its newest brand Noore Hijab Sport. This research was conducted to identify innovation on product innovation, process innovation and marketing innovation which has been done by PT. Dharma Adi Mandiri. In addition, researchers also identified business performance viewed from the aspects of profitability, sales volume and market share. This research is a qualitative research with descriptive presentation. Data obtained by interview, observation and documentation. Sources of data in this study is the owner of PT. Dharma Adi Mandiri, Purchasing and GA in Noore, and Area Manager at Applecoast. The technique of data validity in this study using source triangulation. Based on this research, it can be concluded that PT. Dharma Adi Mandiri has made several innovations on aspects of product innovation, process innovation and marketing innovation. Then business performance at PT. Dharma Adi Mandiri has resulted in better business performance in terms of profitability, sales volume and market share growth. Obstacles in the realization of the product is in the supply chain, it is recommended that PT. Dharma Adi Mandiri is expected to improve supply chain to be efficient.
\end{abstract}

Keywords:business performance, innovation, and MSMES. 


\section{PENDAHULUAN}

Di Indonesia, UMKM mempunyai peran penting dalam peningkatan pertumbuhan ekonomi, hal tersebut dilihat dari segi jumlah usaha baik mikro, usaha kecil maupun usaha menengah yang setiap tahun mengalami peningkatan, Selain itu usaha kecil dan menengah yang inovatif berperan sangat penting terhadap perekonomian Indonesia karena mampu memperluas lapangan kerja; memberikan pelayanan ekonomi secara luas kepada masyarakat; berperan dalam proses pemerataan dan peningkatan pendapatan masyarakat; mendorong pertumbuhan ekonomi dan mewujudkan stabilitas nasional. Usaha kecil, mikro dan menengah juga merupakan salah satu pilar utama ekonomi Indonesia sehingga membutuhkan kesempatan untuk dijadikan prioritas, dukungan, perlindungan, dan pengembangan seluas-luasnya (Dhewanto et al. (2015:33).

Dengan meningkatnya jumlah UMKM, seorang pelaku UMKM atau unit usaha harus berfikir secara kreatif dan inovatif untuk meningkatkan kinerja usahanya agar tidak kalah bersaing dengan saingannya serta mensukseskan kegiatan usahanya terlebih di Indonesia ini, dimana pasar akan terus mengalami pertumbuhan dan bergerak sengat dinamis. Bagi perusahaan kecil (small business) inovasi merupakan jantung bagi kemampuan perusahaan kecil untuk dapat bersaing dengan pesaing mereka (Hadiyati, 2012). Inovasi adalah kemampuan untuk menerapkan solusi kreatif terhadap masalah dan peluang untuk meningkatkan atau untuk memperkaya kehidupan manusia (Scarborough \& Cornwall, 2016:57). Kunci untuk dapat bertahan tumbuh, dan tetap menguntungkan adalah dengan terus menerus berinovasi mengembangkan produk dan proses baru (Hartman, Tower dan Sebora dalam Indriani \& Prasetyowati, 2008; Tohidi\& Jabbari, 2012). Georgellis, Joyce dan Woods dalam Hadiyati mengatakan bahwa bisnis entrepreneurial yang digambarkan melalui kapasitasnya membuat rencana ke depan, kapasitasnya dalam berinovasi dan kemauan mengambil resiko, akan memudahkannya berinovasi, dan juga berkembang dan tumbuh dengan sukses. Inovasi adalah karakteristik kunci dari sebuah bisnis entrepreneurial yang mempengaruhi kinerja bisnis.

Kota Bandung yang merupakan salah satu kota tujuan pariwisata di Indonesia yang terkenal dibidang fashion. Hal ini membuktikan bahwa tingkat persaingan indutri fashion di Kota Bandung cukup ketat. Oleh karena itu, semakin banyak pengusaha yang berlomba-lomba untuk masuk kedalam industri kreatif fashion. Mengingat dengan semakin ketatnya persaingan di sebagian pasar saat ini, perusahaan-perusahaan diharapkan terus melakukan inovasi. Perusahaan yang tidak inovatif akan kalah bersaing dengan competitor yang selalu berionovasi.

Dalam penelitian terdahulu menunjukan, bahwa menurut Najib \& Kiminami (2011) menyatakan bahwa inovasi berhubungan positif dengan kinerja bisnis dalam hal profitability relatif, pangsa pasar, dan pertumbuhan. Dengan begitu inovasi dan kinerja bisnis UMKM merupakan keterkaitan yang saling berhubungan satu dengan yang lainnya banyak faktor yang dinilai penting bagi kelangsungan hidup UMKM agar mencapai kesuksesan yang diinginkan. 
Konsep ini di dukung oleh beberapa penelitian terdahulu lainnya seperti Kim (2017), Jaklič, Damijan, Rojec, \& Kunčič (2014), dan Karno \& Purwanto (2017). Menurut Najib \& Kiminami (2011)Kinerja bisnis dioperasionalkan sebagai gabungan tiga ukuran: penjualan volume, profitability, dan pangsa pasar.

Dengan demikian inovasi dalam penelitian ini yang termasuk dalam sektor skala usaha menengah merupakan salah satu faktor penting yang diyakini bisa meningkatkan daya saing perusahaan. Menurut Dhewanto et al. (2015:40) Inovasi biasanya mengacu pada kata sifat seperti: memperbaharui, mengubah, atau membuat proses maupun produk, serta secara dalam melakukan sesuatu sehingga menjadi lebih efektif. Dalam konteks bisnis atau usaha, hal ini bisa berarti menerapkan ide-ide baru, meningkatkan layanan yang ada, serta membuat produk lainnya yang lebih dinamis.

Inovasi yang dimaksud mencakup inovasi produk, inovasi jasa dan inovasi proses. Reguia (2014) mengatakan bahwa inovasi produk adalah pengembangan produk baru, membuat perubahan dalam desain produk saat ini atau menggunakan teknik baru. Inovasi proses adalah implementasi produksi atau metode pengiriman yang benar-benar baru atau peningkatan secara signifikan. Inovasi proses berguna untuk mengurangi biaya produksi dan juga untuk memuaskan para pelanggannya (Hassan, Shaukat, Nawaz, \& Naz, 2013:246). Sedangkan inovasi jasa adalah perubahan yang dilakukan perusahaan untuk meningkatkan kinerja pemasaran dengan mempercepat sistem kerja pelayanan perusahaan melalui berbagai kombinasi baru dari faktor-faktor pelayanan yang ada (Antanegoro, Surya, \& Sanusi, 2017). Inovasi yang tinggi baik itu inovasi proses maupun inovasi produk akan meningkatkan kemampuan perusahaan menciptakan produk yang berkualitas (Hartini, 2012).

Dengan memahami serta menggunakan inovasi dalam bersaing dengan perubahan dalam dunia bisnis yang dinamis, pelaku usaha harus terus maju dengan kekayaan ideide kreatif dan inovatifnya yang dapat dirubah menjadi produk yang kompetitif. Sehingga memungkinkan pengusaha dan usahausaha mereka untuk meningkatkan kinerja bisnis yang dapat membantu meningkatkan perekonomian negara. Kegagalan inovasi akan mengakibatkan hilangnya sejumlah nilai investasi, menurunkan moral kerja, meningkatkan sifat sinis, atau penolakan produk serupa di masa yang akan datang (Hendrayanti, 2011).

Pada penelitian ini akan mengidentifikasi praktik-praktik inovasi yang dilakukan di PT. Dharma Adi Mandiri selain itu belum adanya evaluasi terkait inovasi dari PT. Dharma Adi Mandiri dan mengenai peluncuran brand terbarunya Noore dilihat dari inovasi produk, inovasi proses dan inovasi pemasaran untuk melihat hasil atau output dalam kinerja bisnis yang dilihat dari aspek profitability, sales volume, dan market share yang saat ini telah terealisasi sesuai dengan visi yang dibuat oleh perusahaan.

\section{METODE PENELTIAN}

Metodologi yang digunakan dalam penelitian ini adalah metode penelitian kualitatif dengan tujuan penelitian deskriptif untuk menggambarkan karakteristik atau fungsi dari 
beberapa variabel dalam penelitian. Menurut Indrawati (2015:206) Metode penelitian kualitatif adalah metode penelitian yang melibatkam analisis berupa deskripsi data dan data tersebut tidak secara langsung dapat dikuantifikasi. Jenis penelitian ini berupaya untuk mentransformasikan objek penelitian ke dalam bentuk yang dapat dipresentasikan, seperti catatan lapangan (field note), hasil interview, percakapan, foto-foto, rekaman, dan memo. Berdasarkan keterlibatannya, peneliti harus berinteraksi langsung dengan sumber data.

Berdasarkan unit analisis, maka penelitian dilakukan pada organisasi yaitu dari Owner dan Manajerial intinya di PT. Dharma Adi Mandiri. Berdasarkan waktu pelaksanaan, Cross sectional, yaitu apabila pengumpulan data dilakukan dalam satu periode, kemudian data itu diolah, dianalisis, dan kemudian ditarik kesimpulan penelitian. Teknik pengumpulan data dilakukan dengan, wawancara, dokumentasi dan triangguasi atau menggabungkan hasil data selanjutnya mereduksi data berarti membuat rangkuman, memilih hal-hal pokok, memfokuskan pada hal-hal penting, mencari tema dan pola, serta membuang yang dianggap tidak perlu setelah data direduksi, langkah analisis selanjutnya adalah penyajian (display) data dengan menarik kesimpulan berdasarkan temuan dan melakukan verifikasi data.

\section{HASIL DAN PEMBAHASAN}

Pada tahapan ini, hasil penelitian berupa hasil wawancara, observasi dan dokumentasi foto. Hasil wawancara narasumber akan melalui proses verbatim. Hasil Verbatim diperoleh dari 3 narasumber dari PT. Dharma Adi Mandiri yaitu Owner (N1), Purchasing and General Affair di Noore (N2), dan Area Manajer di Applecoast (N3). Selanjutnya dilakukan reduksi data dengan memilih kata yang penting atau tidak penting melalui proses pengkodean (coding). Berikut ini merupakan kesimpulan wawancara hasil triangulasi narasumber.

Tabel 1. Hasil Penelitian

\begin{tabular}{|c|c|}
\hline Indikator & Kesimpulan \\
\hline \multicolumn{2}{|r|}{ Inovasi Produk } \\
\hline Fitur Produk & $\begin{array}{l}\text { Ide awal inovasi produk berawal dari peluang pasar dan passion terhadap olahraga, Merealisasikan } \\
\text { ide inovasi produk dengan melakukan perencanaan financial, pemasaran dan produksi, untuk Noore } \\
\text { dengan membuka toko sedangkan Applecoast membuat acara dan bekerja sama dengan komunitas } \\
\text { skateboard. evaluasi dilakukan dari penjualan, omset, transaksi dan hasil promo, hambatan terjadi } \\
\text { di supply dan mengalami penurunan rating brand pada Applecoast. Varian produk yang telah } \\
\text { terealisasikan di Noore yaitu hijab, baju renang, tas, baju olahraga, inner, legging, jaket, topi, dan } \\
\text { botol air minum sedangkan Applecoast topi, kemeja, t-shirt, celana, jaket, dompet, dan kaos kaki. } \\
\text { Sedangkan yang belum terealisasikan sepatu dan aksesoris seperti jam dan kacamata. Value yang } \\
\text { ditawarkan yaitu Noore terbuat dari bahan lycra spandex yang mengandung airtech berfungsi sebagai } \\
\text { UV guard, nano guard, thermal tech, lalu harga yang ditawarkan setengah dari harga brand sport } \\
\text { asing, sudah bersertifikat halal, dan sebagai brand hijab pertama di Indonesia untuk olahraga renang, } \\
\text { sedangkan Applecoast merupakan fashionskateboard dan produknya hanya satu tidak pernah ada } \\
\text { repeat. }\end{array}$ \\
\hline Desain Dan Rancangan Produk & $\begin{array}{l}\text { Ide inovasi dalam mendesain terinsiprasi dari idealis owner, lingkungan, gaya hidup, melihat orang } \\
\text { berhijab ketika berolahraga, dari teman - teman kreatif dan mengadopsi dari brand luar. Merealisasikan } \\
\text { ide desain dengan melakukan mencari desainer, mengadakan rapat dengan tim kreatif dan melakukan } \\
\text { persiapan selama } 8 \text { bulan sebelum fase penjualan. Evaluasi dilakukan jika desain yang telah dibuat } \\
\text { tidak laku dipasaran, selain itu melakukan kerja sama dengan atlit dan memastikan timeline produksi } \\
\text { sesuai dengan rencana. Hambatan dalam merealisasikan ide terdapat pemilihan material bahan dan } \\
\text { ketepatan waktu solusi yang ditawarkan dengan mengganti bahan tersebut.Desain yang menjadi ciri } \\
\text { khas dalam produk yaitu desain yang simple dan fungsionalitas produk yang dihasilkan harus sesuai } \\
\text { dengan fungsinya. Rancangan desain produk yang dirancang selalu memiliki fungsi sebagai added } \\
\text { value. Terdapat perencanaan rancangan desain untuk tahun mendatang. }\end{array}$ \\
\hline
\end{tabular}




\begin{tabular}{|c|c|}
\hline Kualitas Produk & $\begin{array}{l}\text { Bahan yang digunakan untuk Noore yaitu lycra, spandex, polyester dan dryfit sedangkan Applecoast } \\
\text { yaitu polyester, oscar, combed, dan cotton.Sumber bahan - bahan produk didapatkan dari pabrik di } \\
\text { Bandung, Indonesia. Menggunakan kualitas no. } 1 \text { namun belum melakukan evaluasi daya tahan } \\
\text { produk karena berdasarkan pemakaian konsumen }\end{array}$ \\
\hline \multicolumn{2}{|r|}{ Inovasi Proses } \\
\hline Metode Produksi & $\begin{array}{l}\text { Alat - alat yang digunakan dalam mendesain untuk technical drawing adalah kertas, pensil, buku } \\
\text { gambar, dan penghapus sedangkan untuk desain grafis menggunakan komputer, wakom dan } \\
\text { aplikasi Adobe. Alat - alat membuat produk untuk cutting yaitu lectra, mesin pola, dan mesin potong } \\
\text { sedangkan Sewing yaitu mesin jahit, benang, jarum, mesin obras, dan overdeck. Alat - alat yang } \\
\text { digunakan dalam packaging yaitu kardus, plastik atau kantong. Tempat menyimpan bahan dan barang } \\
\text { hasil produksi di gudang dan tidak ada alat khusus dalam menyimpan barang dan bahan. }\end{array}$ \\
\hline Metode Distribusi & $\begin{array}{l}\text { Sarana yang digunakan untuk mengantarkan produk menggunakan pihak ketiga seperti JNE, JNT, } \\
\text { GO-JEK dan menggunakan kendaraan sendiri. Cara mengelola persediaan bahan baku produksi } \\
\text { terdapat } 3 \text { proses yaitu Process Order, Receive Order, dan Delivery Order selain itu dilakukan } \\
\text { estimasi persediaan perbulan serta melakukan komunikasi di bagian gudang untuk mendistribusikan } \\
\text { produk yang diminta. }\end{array}$ \\
\hline \multicolumn{2}{|r|}{ Inovasi Pemasaran } \\
\hline Perubahan Desain Produk & $\begin{array}{l}\text { Selalu ada perubahan desain peroduk saat pertama kali diluncurkan hingga saat ini, Perubahan desain } \\
\text { yang dilakukan karena agar memenuhi kebutuhan konsumen dan menyesuaikan dengan pasar yang } \\
\text { ada, perubahan yang dilakukan dalam Noore yaitu dari segi pola, sedangkan Applecoast dari desain } \\
\text { warna dan desain gambar, sehingga dalam merealisasikannya dilakukan FGD atau Focus Group } \\
\text { Discussion. }\end{array}$ \\
\hline Promosi Produk & $\begin{array}{l}\text { Metode promosi yang digunakan yaitu ATL dan BTL iklan seperti Instagram ads, Facebook ads, dan } \\
\text { iklan majalah, ATL (Above The Line) tujuannya untuk mengejar kesadaran konsumen seperti reklame, } \\
\text { baliho, dan tv sedangkan BTL (Below The Line) tujuannya lebih engagement dan selling, selain } \\
\text { itu dengan memanfaatkan teknologi agar masyarakat lebih mudah dalam mengakses.Merealisasikan } \\
\text { metode promosi dengan membuat perencanaan billboard, bekerja sama dengan Elzatta Hijab, dan } \\
\text { memposting foto lalu video produk yang dipakai oleh riders ke media sosial. Evaluasi dilakukan } \\
\text { dari penjualan terbanyak dari Instagram.Hambatan dalam merealisasikan metode promosi yaitu biaya } \\
\text { seperti dari kartu kredit jika limit, dan sulit mempromosikan brand lokal kepada konsumen remaja. }\end{array}$ \\
\hline Harga & $\begin{array}{l}\text { Tidak melakukan custom harga hanya menyediakan kerjasama dengan mitra, distributor dan } \\
\text { kebutuhan produksi dengan desain yang diinginkan, menyesuaikan budget yang tersedia. }\end{array}$ \\
\hline \multicolumn{2}{|r|}{ Kinerja Bisnis } \\
\hline Profitability & $\begin{array}{l}\text { Jumlah omzet penjualan persuahaan dibawah } 1 \text { milyar, selalu mengalami peningkatan sedangkan } \\
\text { Applecoast tidak menentu, biaya mengalami penurunan jika brand sudah diatas } 3 \text { tahun, Pertumbuhan } \\
\text { jumlah profit dari awal berdiri hingga saat ini secara keseluruhan mengalami peningkatan setiap } \\
\text { tahunnya. }\end{array}$ \\
\hline Sales Volume & $\begin{array}{l}\text { Pertumbuhan penjualan jumlah barang mengalami peningkatan sebesar } 2 \% \text { namun di Applecoasttidak } \\
\text { menentu bergantung pada season. }\end{array}$ \\
\hline Market Share & $\begin{array}{l}\text { Selalu mengalami peningkatan dan jumlah pertumbuhan transaksi. Terdapat member di } \\
\text { perusahaandan selalu mengalami peningkatan, keuntungan yang didapatkan pengguna member di } \\
\text { Applecoast terdapat diskon } 30 \% \text { selama } 3 \text { tahun sedangkan Noore mendapatkan loyalty card jika } \\
\text { sudah melakukan transaksi mencapai } 20 \text { kali akan mendapatkan gift dan menjadi prioritas jika } \\
\text { ada informasi mengenai promo lainnya. Target konsumen Noore untuk wanita menengah ke atas } \\
\text { dari usia } 18-35 \text { tahun, kota besar, baru menikah atau sudah merencanakan untuk menikah, sedang } \\
\text { mencari pekerjaan atau sudah bekerja suka bermain internet, mayoritas menggunakan mobile phone } \\
\text { android, memeperhatikan penampilan untuk tampil cantik, sehat dan muda atau jiwa muda sedangkan } \\
\text { Applecoast pria maupun wanita untuk usia } 16-28 \text { tahun. Jumlah konsumen di Kota Bandung jika } \\
\text { dilihat dari parameter penjualan sebesar } 20 \% \text { hingga } 30 \% \text { konsumen }\end{array}$ \\
\hline
\end{tabular}

\section{KESIMPULAN}

Praktik-praktik inovasi yang dilakukan oleh PT. Dharma Adi Mandiri setelah 5 tahun berjalan yaitu dengan membuat inovasi produk, sebuah brandhijab sport bernama Noore, dengan value yang ditawarkan yaitu mengandung teknologi UV Guard, Air Tech, Nano Guard, dan Thermal Tech. Dalam inovasi proses, di metode produksi terdapat 2 cara dalam mendesain produk Jurnal Penelitian Pendidikan yaitu technical drawing dan desain grafis menggunakan wakom. Kemudian dalam membuat produk terdapat pula 2 proses yaitu cutting menggunakanmesin lectra dan sewing menggunakan mesin overdeck. Selain itu, dalam metode distribusi terdapat 3 proses yang dilakukan yaitu Process Order, Receive Order dan Delivery Order. Mengenai inovasi pemasaran, metode promosi yang digunakan oleh PT. Dharma Adi Mandiri menggunakan 
ATL (Above The Line) tujuannya untuk mengejar kesadaran konsumen seperti menggunakan reklame, baliho, dan tv. Lalu BTL (Below The Line) tujuannya lebih kearah engagement dan selling. Kinerja bisnis dari PT. Dharma Adi Mandiri dengan adanya brand Noore, berdasarkan hasil wawancara sudah berjalan dengan baik dan mengalami pertumbuhan, yang mengadopsi praktik inovatif cenderung menghasilkan keunggulan kompetitif dan mengakibatkan kinerja bisnis yang lebih baik lagi.

Adapun saran dari penulis yang ingin disampaikan untuk PT. Dharma Adi Mandiri sehingga dapat membantu keberlangsungan perusahaannya untuk kedepannya mengenai hambatan di supply chain agar menjadi efisien yaitu; 1) Melakukan perencanaan kebutuhan proses produksi yang rutin dilakukan pertahun atau perkuartal pada kegiatan pengadaan barang; 2) Membuat schedule risk dan schedule project sebagai identifikasi resiko yang mungkin terjadi dari penjadwalan yang sudah di rancang; 3) Perusahaan sebaiknya melakukan komunikasi dengan supplier baik dengan menggunakan email, telephone, atau forum antara perusahaan dengan supplier, hal tersebut dilakukan untuk menciptakan hubungan yang lebih dekat dengan pihak supplier agar mengurangi kesalah pahaman informasi antara perusahaan dengan supplier; 4) Perusahaan harus memantau ketepatan waktu dan kualitas barang yang dikirim dari masing-masing supplier; 5) Di dalam internal perusahaan, memungkinkan organisasi untuk membuat alur kerja berjalan secara baik dan benar mengenai analisis pelaksanaan, perencanaan, sumber daya, produksi, pengiriman dan pemeliharaan.

Diharapkan untuk penelitian selanjutnya untuk praktik inovasi diidentifikasi berdasarkan inovasi produk, inovasi proses dan inovasi pemasaran lalu dilihat dari output kinerja bisnis dari aspek profitability, sales volume dan market share. Penulis memberikan saran bagi peneliti selanjutnya untuk dapat menambahkan atau mempertimbangkan variabel inovasi lain, seperti inovasi jasa atau inovasi hijau.

\section{DAFTAR PUSTAKA}

Antanegoro, R. Y., Surya, D., \& Sanusi, F. (2017). Analisis Pengaruh Inovasi Produk, Inovasi Layanan Dan Kualitas Pelayanan Terhadap Kepuasan Dan Loyalitas Nasabah RM. Jurnal Riset Bisnis Dan Manajemen Tirtayasa, 1(02), 167-179.

Dhewanto, W., Indradewa, R., Ulfah, N, W., Rahmawati, S., Yoshanti, G., \& Zendry, G. (2015). Manajemen Inovasi untuk Usaha Kecil dan Mikro. Bandung: Alfabeta.

Hadiyati, E. (2012). Kreativitas Dan Inovasi Pengaruhnya Terhadap Pemasaran Kewirausahaan Pada Usaha Kecil. Jurnal Inovasi Dan Kewirausahaan, 1(3), 135-151.

Hartini, S. (2012). Peran Inovasi: Pengembangan Kualitas Produk dan Kinerja Bisnis. Jurnal Manajemen Dan Kewirausahaan, 14(1), 82-88.

Hassan, M. U., Shaukat, S., Nawaz, M. S., \& Naz, S. (2013). Effects of Innovation Types on Firm Performance: an Empirical Study on Pakistan's Manufacturing Sector. Soc Sci Pakistan Journal of Commerce and Social Sciences, 7(2), 243-262.

Hendrayanti, E. (2011). Inovasi Efektif: Upaya Mempertahankan dan Menangkap Pasar Potensial. Jurna Ilmiah Ekonomi Manajemen Dan Kewirausaan OPTIMAL, 5(1), 91-102.

Indrawati. (2015). Metode Penelitian Manajemen dan Bisnis : Konvergensi Teknologi Komunikasi dan informasi. Bandung : PT Refika Aditama. 
Jaklič, A., Damijan, J. P., Rojec, M., \& Kunčič, A. (2014). Relevance of innovation cooperation for firms' innovation activity: the case of Slovenia. Economic Research-Ekonomska Istraživanja, 27(1), 645-661.

Karno, C. G., \& Purwanto, E. (2017). The Effect of Cooperation and Innovation on Business Performane. Jurnal General Management, 18(158), 123-126.

Kim, K. (2017). Impact of firms' cooperative innovation strategy on technological convergence performance: The case of Korea's ICT industry. Sustainability (Switzerland), 9(9), 1-22.

Indriani, F., \& Prasetyowati, E. (2008). Studi Mengenai Inovasi Produk Pada Usaha Kecil Kerajinan Ukiran Di Jepara. Iurnal Sains Pemasaran Indonesia |r, Vll(2), 249-272.

Najib, M., \& Kiminami, A. (2011). Innovation, Cooperation and Business Performance: Some evidence from Indonesian small food processing cluster. Journal of Agribusiness in Developing and Emerging Economies, 1(1), 75-96.

Reguia, C. (2014). Product Innovation And The Competitive Advantage. European Scientific Journal, ESJ, 10(10), $140-158$.

Scarborough, N. M., \& Cornwall, J. R. (2016). Essentials of entrepreneurship and small business management. (Eighth Edition). London: Pearson.

Tohidi, H., \& Jabbari, M. M. (2012). Product Innovation Performance in Organization. Procedia Technology, 1, 521-523. 